DE

M E D I C I N A

T R O P I C A L

$\mathrm{DE}$

SÃO PAULO

JOURNAL OF THE SÃO PAULO INSTITUTE OF TROPICAL MEDICINE

${ }^{1}$ Instituto Butantan, Divisão de Ensaios Clínicos e Farmacovigilância, São Paulo, São Paulo, Brazil

2Universidade de São Paulo, Faculdade de Medicina, Hospital das Clínicas, Centro de Referência para Imunobiológicos Especiais (CRIE), São Paulo, São Paulo, Brazil

${ }^{3}$ Instituto Adolfo Lutz, Centro de Virologia, São Paulo, São Paulo, Brazil

${ }^{4}$ Universidade de São Paulo, Faculdade de Medicina, Hospital das Clínicas, Instituto da Criança, São Paulo, São Paulo, Brazil

${ }^{5}$ Universidade de São Paulo, Faculdade de Medicina, Departamento de Pediatria, São Paulo, São Paulo, Brazil

Correspondence to: Alexander Roberto Precioso

Instituto Butantan, Divisão de Ensaios

Clínicos e Farmacovigilância, Avenida Vital Brasil, 1500, CEP 05503-900, São Paulo,

SP, Brazil

E-mail: alexander.precioso @ butantan.gov.br

Received: 6 April 2018

Accepted: 2 July 2018

\section{Prospective cohort studies to evaluate the safety and immunogenicity of the 2013, 2014, and 2015 seasonal influenza vaccines produced by Instituto Butantan}

\author{
Gabriella Mondini', Patricia Emilia Braga1', Marta Heloisa Lopes², Ana \\ Marli Christovam Sartori ${ }^{2}$, Karina Takesaki Miyaji ${ }^{2}$, Vanessa Infante ${ }^{2}$, Bruno \\ Azevedo Randi ${ }^{2}$, Maria do Carmo Sampaio Tavares Timenetsky ${ }^{3}$, Juliana \\ Caires de Oliveira Achili Ferreira ${ }^{4}$, Neusa Keico Sakita ${ }^{4}$, Alexander Roberto \\ Precioso ${ }^{1,5}$
}

\section{ABSTRACT}

Annual vaccination is the most effective way to prevent seasonal influenza illness. Instituto Butantan (IB) performed clinical studies with its 2013, 2014 and 2015 seasonal trivalent influenza vaccines (inactivated split-virion). Prospective cohort studies were carried out to describe the safety and immunogenicity of Instituto Butantan influenza vaccines, in healthy adults and elderly, from 2013 to 2015 . Immediately after the informed consent was signed, participants underwent blood collection followed by vaccination. On study days 1 , 2 and 3 post-vaccination participants were contacted by the staff to evaluate the occurrence of solicited (local and systemic) and non-solicited adverse reactions. On study day $21(+7)$ subjects returned to the clinical site for final safety assessments and blood collection to evaluate post-vaccination immunogenicity. The immunogenicity analyses were performed by means of hemagglutination inhibition (HI) assay. The immunogenicity endpoints were: seroprotection (SPR) and seroconversion (SCR) rates and the geometric mean HI antibody titer ratio (GMTR). The 2013 study was conducted at the Centro de Referencia para Imunobiológicos Especiais (CRIE) and at the Centro de Pesquisa Clínica do Instituto da Criança, Hospital das Clínicas da Faculdade de Medicina da Universidade de São Paulo while the 2014 and 2015 studies were conducted at CRIE. The vaccine composition followed the WHO recommendation for the Southern hemisphere seasonal influenza vaccine. Fortyseven healthy adults and 13 elderly participated in the 2013 study, 60 healthy adults and 60 elderly in the 2014 study, and 62 healthy adults and 57 elderly in the 2015 study. In the 2013 , 2014 and 2015 studies, pain was the most frequent local adverse reaction and headache the most frequent systemic adverse reaction. All observed adverse reactions were classified as mild or moderate and none as severe. SPR $>70 \%$ and SPR $>60 \%$ were observed in adults and elderly, respectively, for the three vaccine viruses, in the 2013, 2014 and 2015 studies. SCR $>40 \%$ was observed in adults, for the three vaccine viruses, only in the 2014 study and SCR $>30 \%$ was observed in the elderly, for the three vaccine viruses, only in the 2013 and 2014 studies. GMTR > 2.5 among adults, for the three vaccine viruses was only observed in the 2013 study and GMTR > 2.0 was observed among elderly, for the three vaccine viruses, in the 2013, 2014 and 2015 studies. The 2013, 2014 and 2015 seasonal influenza vaccines produced by Instituto Butantan were safe and immunogenic according to the immunogenicity criteria defined by the European Medicines Agency (EMA).

KEYWORDS: Seasonal influenza vaccine. Vaccine immunogenicity. Vaccine safety. Cohort studies. Adults. Elderly. 


\section{INTRODUCTION}

Influenza or Flu is a viral disease of high transmissibility that affects the respiratory tract of people at any age and has global distribution. According to the World Health Organization (WHO), this disease results in 3 to 5 million of serious cases and 250,000 to 500,000 deaths, annually ${ }^{1}$.

People at increased risk to develop complications associated with influenza virus include adults older than 65 years, pregnant women, immunocompromised patients, people with chronic underlying medical conditions, children under 5 years of age and health care professionals ${ }^{2,3}$.

Annual vaccination is recommended by $\mathrm{WHO}$ as the most effective way of preventing seasonal influenza. In Brazil, the National Immunization Program (NIP) of the Ministry of Health has carried out annual national influenza vaccine campaigns since 1999. In the first national immunization campaign, the NIP recommended vaccination only for adults over 65 years of age, however, the recommendation has progressively been expanded to other target groups such as children 6 months to 5 years, adults over 60 years, pregnant women, women in the post-partum period (up to 45 days), healthcare professionals, indigenous people, people from 12 to 21 years under socio-educational programs (adolescents being followed in freedom or not for different kind of conflicts with law), people deprived of freedom, employees of the prison system, people with chronic and/or other medical conditions ${ }^{4}$. In Brazil, the NIP has provided the inactivated split-virion seasonal trivalent influenza vaccine (inactivated split-virion) free of charge to the target populations ${ }^{5}$.

Instituto Butantan (IB) is a public Brazilian biomedical research manufacturer center affiliated to the Sao Paulo State Secretary of Health. Currently, it is one of the main public producers of vaccines, antivenoms, and antitoxins in Latin America.

From 2013 to 2015, the IB's Division of Clinical Trials and Pharmacovigilance performed prospective cohort studies to evaluate the safety and immunogenicity of the 2013, 2014, and 2015 seasonal trivalent influenza vaccines (inactivated split-virion) in health adults and people over 60 years of age. Here, we describe the results of those studies, which were requested by the Brazilian regulatory health authority (Agência Nacional de Vigilância Sanitária - ANVISA).

\section{MATERIAL AND METHODS}

\section{Study designs}

In 2013, 2014, and 2015 we performed prospective cohort studies. The 2013 study was conducted at the Centro de Referência de Imunobiológicos Especiais (CRIE) and at the Centro de Pesquisa Clínica do Instituto da Criança (ICR) both from the Hospital das Clínicas da Faculdade de Medicina da Universidade de São Paulo (HCFMUSP). However, the 2014 and 2015 studies were conducted exclusively at CRIE. The three studies were performed within the period of the Brazilian national immunization campaign for influenza, and all were approved by the Ethics Committee of the Faculdade de Medicina da Universidade de São Paulo and were registered at ClinicalTrials.gov (2013 study: NCT02819115, 2014 study: NCT02819180, and 2015 study: NCT 02313740). The three studies were conducted in accordance with the principles of the Declaration of Helsinki, Good Clinical Practices ${ }^{6}$, Resolution 466/2012 of the Brazilian National Health Council (CNS) on ethics in human research and financially sponsored by Butantan Foundation.

\section{Subjects and study procedures}

Healthy, male and non-pregnant female between 18 and 59 years of age, and elderly over 60 years of age were eligible for enrollment and the participants were selected based on inclusion and exclusion criteria (described below). All participants provided written informed consent and were invited to participate at the time they presented spontaneously at the clinic where the study was taking place. These predefined age groups followed the recommendation by the European Medicines Agency (EMA) for studies of seasonal influenza vaccines ${ }^{7,8}$.

Inclusion criteria:

1. Healthy adults, male or female aged 18 to 59 or elderly aged 60 years and above;

2. To be available to participate in the study throughout its duration (approximately 21 days);

3. To have medical indication to be vaccinated against influenza;

4. To demonstrate intention to participate in the study, as documented by the signature in the study's informed consent form (ICF).

Exclusion criteria:

1. Evidence of active neurological, cardiac, pulmonary, hepatic or renal disease as clinical history and/or physical examination (except hypertension under control among the elderly);

2. Compromised immune system diseases including: HIV, diabetes mellitus, cancer (except basal cell carcinoma) and autoimmune diseases;

3. Behavioral, cognitive or psychiatric disease that in the opinion of the principal investigator or his representative physician, affects the participant ability to understand and cooperate with all study protocol requirements; 
4. Alcohol or drugs abuse in the past 12 months that has caused medical, professional or family problems, indicated by clinical history;

5. Known systemic hypersensitivity to eggs or to any component of the vaccine;

6. History of severe adverse reaction after previous administration of an Influenza vaccine within 6 weeks following vaccination;

7. History of Guillain-Barré Syndrome or other demyelinating disease;

8. Diagnosis of asthma with a history of hospitalization in the last six months due to the illness;

9. Suspected or confirmed fever in the 3 days prior to vaccination or axillary temperature greater than $37.8^{\circ} \mathrm{C}$ on the day of vaccination;

10. Use of corticosteroids (except topical or nasal) or other immunosuppressive drugs within 42 days before the study initiation/baseline. It will be considered immunosuppressive dose of corticosteroids the equivalent to a dose $\geq 10 \mathrm{mg}$ of prednisone per day for over 14 days;

11. Impaired coagulation due to chronic disease or due to the use anticoagulant medication (warfarin or heparin) in the 7 days preceding vaccination;

12. Have received live virus vaccine within 28 days or killed virus vaccine in the last 14 days prior to vaccination, or having a scheduled immunization during the first 21 days after vaccination;

13. Have received influenza vaccine in the past 6 months;

14. History of asplenia;

15. Have received blood products in the past 6 months, including transfusions or immunoglobulin, or scheduled administration of blood products or immunoglobulin for the first 21 days after vaccination;

16. have a counter indication for Influenza vaccination, including allergy to egg proteins;

17. Use of any investigational product within 42 days before vaccination;

18. Any other condition that might put in risk the safety/ rights of a potential participant or hurdle his/her compliance with this protocol in the investigator's opinion or his representative physician.

\section{Procedures}

Participants were included in the study soon after their inclusion, exclusion criteria were checked and the informed consent signed. A blood sample of $5 \mathrm{ml}$ was taken before vaccination and on day $21(+7)$ post-vaccination (for immunogenicity analysis). Participants received one dose of the vaccine intramuscularly and were observed for $30 \mathrm{~min}$ at the research clinical site. Before leaving, they were oriented to take the axillary temperature and record it in the participant card for the following three days. Fever was defined as an axillary temperature $\geq 37.8^{\circ} \mathrm{C}$. Participants were also contacted by telephone three days after vaccination to check the occurrence of any unsolicited and solicited local (pain, bruising, redness, and swelling), and systemic (fever, chills, myalgia, fatigue, and headache) adverse reactions (AR). On day $21(+7)$ post-vaccination participants returned to the research clinic for the postvaccination immunogenicity analysis and to check the participant card.

\section{Endpoints}

\section{Safety endpoint}

The primary safety endpoints were solicited and unsolicited local and systemic adverse reactions reported by the participants until day 3 after vaccination. Adverse reactions were defined as adverse events that had reasonable causal relationship to vaccination, as defined by the adapted classification of "Uppsala Monitoring Centre" of the World Health Organization". The intensity of adverse reactions was classified as grade one to four according to the Toxicity Grading Scale for Healthy Adult and Adolescent Volunteers Enrolled in Preventive Vaccine Clinical Trials of the US Food and Drug Administration (FDA) ${ }^{10}$.

\section{Immunogenicity endpoints}

The three co-primary immunogenicity endpoints were the proportion of participants that presented seroconversion (pre-vaccination hemagglutination inhibition (HI) antibody titer $<1: 10$ and post-vaccination HI antibody titer $\geq 1: 40$, or pre-vaccination HI antibody titer $<1: 10$ and a post-vaccination increase by a factor of four or more), the proportion of participants with seroprotection (postvaccination $\mathrm{HI}$ antibody titer $\geq 1: 40$ ), and the factor increase in the geometric mean titer, all measured before and 21 days after each vaccination.

The immunological criteria for evaluation of influenza vaccines were based on the Note for Guidance on Harmonization of Requirements for Influenza Vaccines of "The European Medicines Agency (EMA)"7. According to EMA a seasonal influenza vaccine is considered immunogenic when one of the immunogenicity endpoints is demonstrated accordingly with the age ${ }^{7}$. The immunological criteria for the evaluation of seasonal influenza vaccines are described in Table 1.

\section{Laboratory assays}

Anti-influenza antibody response was measured by the 
Table 1 - Immunological criteria for the evaluation of seasonal influenza vaccines

\begin{tabular}{lcc}
\hline $\begin{array}{l}\text { Parameters - one or more of the } \\
\text { following: }\end{array}$ & $\begin{array}{c}\mathbf{1 8 - 6 0} \\
\text { years }\end{array}$ & $\begin{array}{c}>60 \\
\text { years }\end{array}$ \\
\hline Seroconversion rate (SCR) & $>40 \%$ & $>30 \%$ \\
Geometric mean titer ratio (GMTR) & $>2.5$ & $>2.0$ \\
Seroprotection rate (SPR) & $>70 \%$ & $>60 \%$ \\
\hline
\end{tabular}

hemagglutination-inhibition assay, according to standard method at Adolfo Lutz Institute (IAL) (Sao Paulo, Brazil). Titers were tested at an initial dilution of 1:10, and at a final dilution of 1:2,560. For the purposes of calculation, negative titers were assigned a value of 1:5 and those with titers above 1:2,560 had assigned a value of 1:2,560. Samples were tested in duplicate, and the geometric mean value was used in the analyses ${ }^{7,11}$.

\section{Vaccines}

The composition of seasonal trivalent influenza vaccines (inactivated split-virion) produced by IB and evaluated in this study followed the WHO composition recommendation for the Southern Hemisphere. Their compositions were: 2013 (A/California/7/2009 (H1N1) pdm09-like virus; A/Victoria/361/2011 (H3N2)-like virus B/Wisconsin/1/2010-like virus); 2014 (A/California/7/2009 (H1N1)pdm09-like virus' A/Texas/50/2012 (H3N2)like virus. B/Massachusetts/2/2012-like virus), and 2015 (A/California/7/2009 (H1N1)pdm09-like virus; A/Switzerland/9715293/2013 (H3N2)-like virus; B/Phuket/3073/2013-like virus. The vaccines were formulated in a 10-dose vials $(0.5 \mathrm{~mL}$ per dose $)$ and stored at $2-8{ }^{\circ} \mathrm{C}$ until used.

\section{Sample size}

The planned sample size for the 2013 study was 100 participants (50 adults and 50 elderly) and for the 2014 and 2015 studies, 120 participants (60 adults and 60 elderly). These sample sizes were accepted by ANVISA and followed the $\mathrm{EMA}^{7}$ recommendation to demonstrate safety and immunogenicity of seasonal influenza vaccine.

\section{Statistical analysis}

In this study, we performed a descriptive statistical analysis stratified by participants age groups: adults up to 59 years and elderly above 60 years. The demographic characteristics of the participants were described by percentage (gender and ethnicity) and by estimated measures of central tendency and dispersion (age).

For each study year sex, ethnicity and number of participants with adverse reactions were compared between groups using Chi-square test or Fisher's exact test.

The safety analysis was described to all participants using the percentages of adverse reactions (AR), solicited and non-solicited, by age group and study year. These frequencies were compared by the Chi-square test or the Fisher's exact test.

The immunogenicity endpoints were analyzed for each age group, by influenza vaccine strain and study year. In the immunogenicity analysis, only participants with pre and post-vaccination blood samples available were included.

The geometric mean HI antibody titer, pre- and postvaccination, and the GMTR were calculated with respective 95\% confidence intervals (CI). The SCR, SPR and the proportion of participants with pre-vaccination $\mathrm{HI}$ antibody titer $\geq 1: 40$ were also calculated with the respective $95 \%$ CI.

To each age group, by study year and influenza vaccine strain the percentages of SCR, SPR and the GMTR were calculated stratified by pre-vaccination HI antibody titer results $(<1: 40$ or $\geq 1: 40)$. The Mann-Whitney test was used to assess the significance of differences in GMTR between strata. SCRs were compared using the the Fisher's exact test.

Statistical analyses were performed using a significance level of 5\%. The software Stata 13.0 (StataCorp LP, College Station, Texas USA) was used in the analyses.

\section{RESULTS}

\section{Study participants}

The 2013, 2014, and 2015 studies were performed from June 4 to July $27^{\text {th }}$, April $22^{\text {nd }}$ to June, and May $23^{\text {rd }}$ to June $23^{\text {rd }}$, respectively. The participant demographic characteristics are described in Table 2. The total number of participants included in the safety and immunogenicity analysis is described in Figure 1.

In 2013, 63 volunteers agreed to participate in the study and signed the informed consent (63\% of the planned sample size): 50 adults and 13 elderly. However, only 47 (94\%) adults were included in the safety analysis, since two of them had been vaccinated with an influenza vaccine not produced by IB and one participant presented with high blood pressure on the vaccination day and, therefore, was not vaccinated. The median age of the adults was 33.3 years, and the elderly 67.8 years. Only $13(26 \%)$ of the elderly participants agreed to participate in the study and signed the informed consent and all were included in the safety analysis.

In 2014,120 volunteers agreed to participate in the study 
Table 2 - Demographic characteristics of participants according to the vaccination study year and age group

\begin{tabular}{|c|c|c|c|c|c|c|c|c|c|}
\hline \multirow{2}{*}{ VARIABLES } & \multicolumn{3}{|c|}{$\begin{array}{c}2013 \text { Study } \\
n=60\end{array}$} & \multicolumn{3}{|c|}{$\begin{array}{c}2014 \text { Study } \\
n=120\end{array}$} & \multicolumn{3}{|c|}{$\begin{array}{c}2015 \text { Study } \\
n=119\end{array}$} \\
\hline & $\begin{array}{l}\text { Adults } \\
(n=47)\end{array}$ & $\begin{array}{c}\text { Elderly } \\
(n=13)\end{array}$ & $p^{*}$ & $\begin{array}{l}\text { Adults } \\
(n=60)\end{array}$ & $\begin{array}{l}\text { Elderly } \\
(n=60)\end{array}$ & $p^{* *}$ & $\begin{array}{l}\text { Adults } \\
(\mathrm{n}=62)\end{array}$ & $\begin{array}{l}\text { Elderly } \\
(n=57)\end{array}$ & $p^{* *}$ \\
\hline Age $\left(P_{50}\left(P_{25}-P_{75}\right)\right)$ & $\begin{array}{c}33.3 \\
(25.3-44.8)\end{array}$ & $\begin{array}{c}67.8 \\
(62.3-70.0)\end{array}$ & NA & $\begin{array}{c}30.1 \\
(27.2-42.4)\end{array}$ & $\begin{array}{c}66.9 \\
(62.9-73.1)\end{array}$ & NA & $\begin{array}{c}31.5 \\
(27.7-42.0)\end{array}$ & $\begin{array}{c}68.3 \\
(65.5-75.0)\end{array}$ & NA \\
\hline $\operatorname{Sex}(n(\%))$ & & & 0.045 & & & 0.845 & & & 0.725 \\
\hline Female & $29(61.7)$ & $12(92.3)$ & & $41(68.3)$ & $40(66.7)$ & & $40(64.5)$ & $35(61.4)$ & \\
\hline Male & $18(38.3)$ & $1(7.7)$ & & $19(31.7)$ & $20(33.3)$ & & $22(35.5)$ & $22(38.6)$ & \\
\hline Ethnicity (n (\%)) & & & $0.159^{\star \star *}$ & & & $0.001^{* * *}$ & & & $0.977^{\star \star \star}$ \\
\hline White & $38(80.8)$ & $8(61.5)$ & & $42(70.0)$ & $24(40.0)$ & & $48(77.4)$ & $44(77.2)$ & \\
\hline Black & $2(4.3)$ & - & & $4(6.7)$ & $2(3.3)$ & & $1(1.6)$ & $2(3.5)$ & \\
\hline Multirracial & $3(6.4)$ & $1(7.7)$ & & $1(1.7)$ & $1(1.7)$ & & $9(14.5)$ & $2(3.5)$ & \\
\hline Asian & $4(8.5)$ & $2(15.4)$ & & $4(6.6)$ & $2(3.3)$ & & $4(6.5)$ & $8(14.0)$ & \\
\hline Other & - & $2(15.4)$ & & $9(15.0)$ & $31(51.7)$ & & - & $1(1.8)$ & \\
\hline
\end{tabular}

NA: Not Applicable; $\left({ }^{*}\right)$ Fisher's exact test; $\left({ }^{* \star}\right)$ Chi-square test; $\left({ }^{\star \star *}\right)$ white $\mathrm{x}$ others
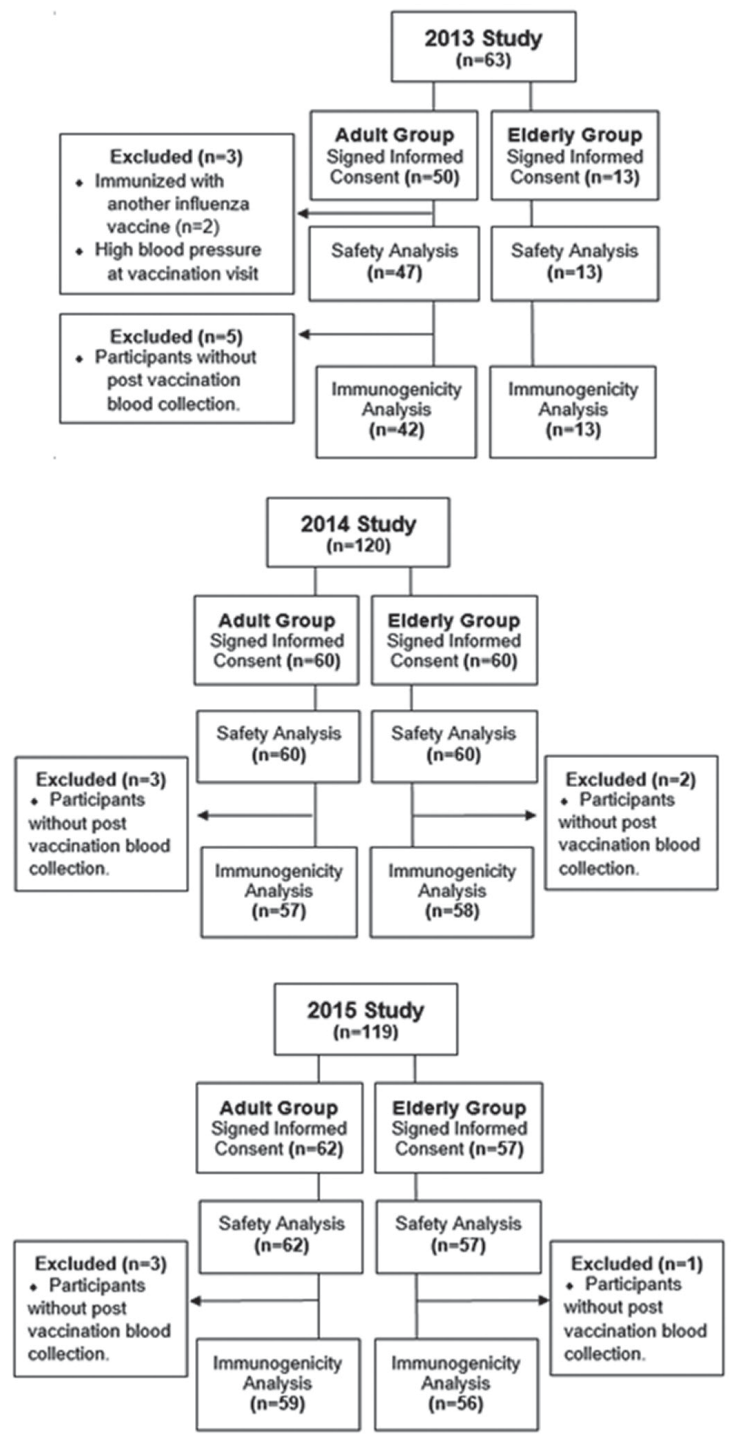

Figure 1 - Flowchart with the number of participants included and analyzed by the study endpoints, year and age group and signed the informed consent. All of them were included in the safety analysis. The median age of the adults was 30.1 years and the elderly 66.9 years.

In 2015, 120 agreed to participate in the study and signed the informed consent, however, only 119 (99.2\%) were included in the safety analysis, 62 adults and 57 elderly. One participant was excluded from safety analysis because he was vaccinated with an influenza vaccine not produced by IB. The median age of the adults was 31.5 and the elderly 68.3 years.

\section{Safety data}

Table 3 shows the descriptive statistical analysis of the adverse reactions according to study year and age group. Table 4 shows the descriptive statistical analysis of the local and systemic solicited and non-solicited adverse reactions, by study year and age group.

In the 2013 study, the total number of adult and elderly participants with ARs was 24 (51\%) and four (30.8\%), respectively. There was no significant statistical difference in the incidence of ARs between adults and elderly $(p=0,226)$. The total number of ARs was 40, $34(85 \%)$ in adults and six $(15 \%)$ in the elderly. The mean number of ARs was 1.4 per adult and 1.5 per elderly. Thirty-two (94.1\%) out of 34 ARs observed in adults were classified as grade I (mild) and two (5.9\%) as grade II (moderate). All adverse reactions reported by the elderly were classified as grade I (mild). The mean interval between the time of vaccination and the onset of ARs in adults was 1.2 days and in the elderly 0.3 days. The mean duration of the ARs among adults was one day and among the elderly 6.5 days. Pain at the injection site and headache were the most frequent solicited, local and systemic ARs in both adults and elderly. 
Table 3 - Statistical analysis of the adverse reactions according to study year and age group

\begin{tabular}{|c|c|c|c|c|c|c|c|c|c|}
\hline \multirow{2}{*}{ VARIABLES } & \multicolumn{3}{|c|}{$\begin{array}{c}2013 \text { Study } \\
n=60\end{array}$} & \multicolumn{3}{|c|}{$\begin{array}{c}2014 \text { Study } \\
n=120\end{array}$} & \multicolumn{3}{|c|}{$\begin{array}{c}2015 \text { Study } \\
n=119\end{array}$} \\
\hline & $\begin{array}{l}\text { Adults } \\
(\mathrm{n}=47)\end{array}$ & $\begin{array}{l}\text { Elderly } \\
(n=13)\end{array}$ & $p^{*}$ & $\begin{array}{l}\text { Adults } \\
(\mathrm{n}=60)\end{array}$ & $\begin{array}{l}\text { Elderly } \\
(\mathrm{n}=60)\end{array}$ & $p^{*}$ & $\begin{array}{l}\text { Adults } \\
(\mathrm{n}=62)\end{array}$ & $\begin{array}{l}\text { Elderly } \\
(n=57)\end{array}$ & $p^{*}$ \\
\hline
\end{tabular}

N of participants with $24(51.0 \%) 4(30.8 \%) \quad p=0.226^{*} 41(68.3 \%) 16(26.7 \%) \quad p<0.001^{\star *} 33(53.2 \%) 16(28.1 \%) \quad p=0.005^{\star \star}$ ARs

\begin{tabular}{|c|c|c|c|c|c|c|}
\hline $\mathrm{N}$ of ARs & 34 & 6 & 85 & 25 & 61 & 34 \\
\hline \multicolumn{7}{|l|}{$\begin{array}{l}\mathrm{N} \text { of ARs per } \\
\text { participant }\end{array}$} \\
\hline mean $(\mathrm{sd})$ & $1.4(0.7)$ & $1.5(0.6)$ & $2.1(1.4)$ & $1.6(1.2)$ & $1.8(1.5)$ & $2.1(1.8)$ \\
\hline median (min-max) & $1(1-3)$ & $1.5(1-2)$ & $1(1-5)$ & $1(1-5)$ & $1(1-8)$ & $1.5(1-7)$ \\
\hline \multicolumn{7}{|l|}{ ARs grade/intensity } \\
\hline 1 & $32(94.1 \%)$ & $6(100 \%)$ & $85(100 \%)$ & $25(100 \%)$ & $49(80.3 \%)$ & $24(70.6 \%$ \\
\hline 2 & $2(5.9 \%)$ & - & - & - & $12(19.7 \%)$ & $10(29.4 \%$ \\
\hline \multicolumn{7}{|l|}{$\begin{array}{l}\text { AR onset (days) from } \\
\text { vaccination }\end{array}$} \\
\hline mean $(s d)$ & $1.2(0.9)$ & $0.3(0.8)$ & $0.4(0.6)$ & $0.6(0.9)$ & $0.8(0.8)$ & $0.4(0.8)$ \\
\hline median (min-max) & $1(0-3)$ & $0(0-2)$ & $0(0-3)$ & $0(0-3)$ & $1(0-3)$ & $0(0-3)$ \\
\hline \multicolumn{7}{|l|}{ ARs duration (days) } \\
\hline mean $(\mathrm{sd})$ & $1.0(2.2)^{+}$ & $6.5(9.3)^{++}$ & $1.9(1.2)$ & $2.0(1.2)$ & $1.4(4.4)$ & $1.1(1.0)$ \\
\hline median (min-max) & $0(0-12)^{+}$ & $3(0-20)^{++}$ & $2(0-7)$ & $2(0-6)$ & $1(0-34)$ & $1(0-3)$ \\
\hline
\end{tabular}

Abbreviation: AR, adverse reaction. $\left({ }^{*}\right)$ Fisher's exact test; $\left({ }^{\star \star}\right)$ Chi-square test; $\left({ }^{\star \star *}\right)$ Among those who presented AR. $(+) 4$ ARs with missing data, (++) 2 ARs with missing data.

Table 4 - Local and systemic solicited and non-solicited adverse reactions according to the study year and age group

\begin{tabular}{|c|c|c|c|c|c|c|c|c|c|}
\hline \multirow[b]{2}{*}{ Adverse Reactions } & \multicolumn{3}{|c|}{2013 Study } & \multicolumn{3}{|c|}{2014 Study } & \multicolumn{3}{|c|}{2015 Study } \\
\hline & $\begin{array}{l}\text { Adults } \\
(n=47)\end{array}$ & $\begin{array}{l}\text { Elderly } \\
(n=13)\end{array}$ & $p^{*}$ & $\begin{array}{l}\text { Adults } \\
(\mathrm{n}=60)\end{array}$ & $\begin{array}{l}\text { Elderly } \\
(n=60)\end{array}$ & $p^{* *}$ & $\begin{array}{l}\text { Adults } \\
(\mathrm{n}=62)\end{array}$ & $\begin{array}{l}\text { Elderly } \\
(\mathrm{n}=57)\end{array}$ & $p^{* *}$ \\
\hline \multicolumn{10}{|c|}{ Solicited reactions } \\
\hline \multicolumn{10}{|l|}{ Local } \\
\hline Pain & 15 (31.9) & $2(15.4)$ & 0.314 & $40(66.7)$ & $12(20.0)$ & $<0.001$ & $29(46.8)$ & $13(22.8)$ & 0.007 \\
\hline Erythema & $1(2.1)$ & - & 0.596 & - & - & - & $1(1.6)$ & $2(3.5)$ & 0.606 \\
\hline Swelling & - & - & - & $2(3.3)$ & - & 0.496 & $4(6.5)$ & $2(3.5)$ & 0.681 \\
\hline Induration & $1(2.1)$ & - & 0.296 & $6(10.0)$ & $3(5.0)$ & 0.491 & $3(4.8)$ & $1(1.8)$ & 0.620 \\
\hline Ecchymosis & - & $1(7.7)$ & 0.217 & $2(3.3)$ & $1(1.7)$ & $>0.999$ & $1(1.6)$ & $1(1.8)$ & $>0.999$ \\
\hline \multicolumn{10}{|l|}{ Systemic } \\
\hline Fever & $3(6.4)$ & - & 0.350 & $1(1.7)$ & $2(3.3)$ & $>0.999$ & $3(4.8)$ & $3(5.3)$ & $>0.999$ \\
\hline Chills & $1(2.1)$ & - & 0.596 & $5(8.3)$ & - & 0.057 & $1(1.6)$ & $3(5.3)$ & 0.348 \\
\hline Headache & $4(8.5)$ & $1(7.7)$ & 0.925 & $11(18.3)$ & $3(5.0)$ & 0.086 & $7(11.3)$ & $4(7.0)$ & 0.533 \\
\hline Fatigue & - & - & - & 8 (13.3) & $2(3.3)$ & 0.047 & $2(3.2)$ & $1(1.8)$ & $>0.999$ \\
\hline Myalgia & - & - & - & $10(16.7)$ & $2(3.3)$ & 0.029 & $5(8.1)$ & $2(3.5)$ & 0.442 \\
\hline \multicolumn{10}{|c|}{ Unsolicited reactions } \\
\hline Sore throat & $2(4.2)$ & - & $>0.999$ & - & - & - & - & - & - \\
\hline Cough & $3(6.4)$ & - & $>0.999$ & - & - & - & - & - & - \\
\hline Rhinorrhoea & $3(6.4)$ & $1(7.7)$ & $>0.999$ & - & - & - & - & - & - \\
\hline Dry mouth & - & - & - & - & - & - & $1(1.6)$ & - & $>0.999$ \\
\hline Arthralgia & - & - & - & - & - & - & $1(1.6)$ & - & $>0.999$ \\
\hline Insonmnia & - & - & - & - & - & - & $1(1.6)$ & - & - \\
\hline Nausea & - & - & - & - & - & - & - & $1(1.8)$ & 0.479 \\
\hline Pruritus & $1(2.1)$ & $1(7.7)$ & 0.389 & - & - & - & - & - & - \\
\hline Local Pruritus & - & - & - & - & - & - & $2(3.2)$ & $1(1.8)$ & $>0.999$ \\
\hline
\end{tabular}

$\left({ }^{\star}\right)$ Fisher's exact test; $\left({ }^{* *}\right)$ Chi-square test 
There was no significant statistical difference with respect the incidence of local and systemic solicited ARs between adults and elderly.

In the 2014 study, the total number of adult and elderly participants with ARs was 41 (68.3\%) and 16 (26.7\%), respectively. The incidence of ARs was statistically significant higher among adults when compared to elderly $(p<0.001)$. The total number of ARs was 110, 85 (77.3\%) in adults and $25(22.7 \%)$ in the elderly. The mean number of ARs was 2.1 per adult and 1.6 per elderly. All the ARs observed in adults and elderly were classified as grade I (mild). The mean interval between the time of vaccination and the onset of ARs in adults was 0.4 days and in the elderly 0.6 days. The mean duration of the ARs among adults was 1.9 day and among elderly 2.0 days. Pain at the injection site and headache were the most frequent solicited, local and systemic ARs in both adults and elderly. Pain at the injection site $(p<0.001)$, fatigue $(p<0.047)$ and myalgia $(p<0.029)$ were statistically more frequent in adults when compared to elderly.

In the 2015 study, the total number of adult and elderly participants was $33(53.2 \%)$ and $16(28.1 \%)$, respectively. The incidence of ARs was statistically significant higher among adults when compared to elderly $(p=0.005)$. The total number of ARs was 95, being $61(64.2 \%)$ in adults and $34(35.8 \%)$ in the elderly. The mean number of ARs was 1.8 per adult and 2.1 per elderly. Forty-nine (80.3\%) out of 61 ARs observed in adults were classified as grade I (mild) and $12(19.7 \%)$ as grade II (moderate). Twenty-four (70.6\%) out of 34 ARs observed in the elderly were classified as grade I (mild) and 10 (29.4\%) as grade II (moderate). The mean interval between the time of vaccination and the onset of ARs in adults was 0.8 days and in the elderly 0.4 days. The mean duration of the ARs among adults was 1.4 day and among the elderly 1.1 days. Pain at the injection site and headache were the most frequent solicited, local and systemic ARs in both adults and elderly. Pain at the injection site $(p<0.007)$ was statistically more frequent in adults when compared to elderly.

\section{Immunogenicity data}

Tables 5 and 6 show the immunogenicity results of 2013 , 2014 and 2015 studies.

In the 2013 study, only 55 (91.7\%) out of 60 participants had pre and post-vaccination blood samples collected, therefore were included in the immunogenicity analysis: 42 adults and 13 elderly. Before immunization, 50\% of the adults had $\mathrm{HI}$ antibodies titers $\geq 1: 40$ for $\mathrm{H} 1 \mathrm{~N} 1, \mathrm{H} 3 \mathrm{~N} 2$, and influenza B viruses; among elderly, 53.8\% had HI antibodies titers $\geq 1: 40$ for $\mathrm{H} 1 \mathrm{~N} 1$ virus and $30.8 \%$ for $\mathrm{H} 3 \mathrm{~N} 2$ and influenza B viruses (Table 5). In adults SPR $>70 \%$, SCR $>40 \%$ and GMTR $>2.5$ were described for the three vaccine viruses (Table 5). Adults with pre-immunization HI antibodies titers $<1: 40$ had significantly higher GMTRs for the three vaccine antigens when compared to those with preimmunization $\mathrm{HI}$ antibodies titers $\geq 1: 40$ (H1N1: $p<0.001$; H3N2: $p=0.023$; B: $p<0.001$ ) (Table 6).

The SCR for H1N1 vaccine virus was also significantly higher among the adults with pre-immunization HI antibodies titers $<1: 40$ when compared to those with pre-immunization HI antibodies titers $\geq 1: 40 \quad(p<0.001)$. However, there was no significant statistical difference in the SCR for H3N2 $(p=0.454)$ and for influenza B $(p=0.005)$ vaccine viruses regardless the pre-immunization HI antibodies titers (Table 6). In the elderly, SPR $>60 \%$, SCR $>30 \%$ and GMTR $>2.0$ were described for the three vaccine viruses (Table 5). The elderly with pre-immunization HI antibodies titers $<1: 40$ had significantly higher GMTRs for $\mathrm{H} 1 \mathrm{~N} 1$ and $\mathrm{H} 3 \mathrm{~N} 2$ vaccine viruses when compared to those with pre-immunization $\mathrm{HI}$ antibodies titers $\geq 1: 40$ ( $p<0.009$ and $p=0.011$, respectively) (Table 6). However, there was no significant statistical difference in the GMTR for influenza B vaccine virus ( $p=0.337)$ regardless of the pre-immunization $\mathrm{HI}$ antibodies titers (Table 6).

The SCR for the H3N2 vaccine virus was also statistically higher among the elderly with pre-immunization HI antibodies titers $<1: 40$ when compared to those with pre-immunization HI antibodies titers $\geq 1: 40 \quad(p=0.007)$. However, there was no statistically significant difference in the SCR for the H1N1 $(p=0.192)$ and influenza B $(p=0.530)$ vaccine viruses regardless of the pre-immunization HI antibodies titers (Table 6).

In the 2014 study, 115 (95.8\%) out of 120 participants completed their pre-vaccination and post-vaccination blood sample collection and, therefore, were included in the immunogenicity analysis: 57 adults and 58 elderly. Before immunization, $84.2 \%$ of the adults had $\mathrm{HI}$ antibodies titers $\geq 1: 40$ for $\mathrm{H} 1 \mathrm{~N} 1$ virus, $77.2 \%$ for $\mathrm{H} 3 \mathrm{~N} 2$ virus, and $87.7 \%$ for influenza B virus; among the elderly, 56.9\% had HI antibodies titers $\geq 1: 40$ for $\mathrm{H} 1 \mathrm{~N} 1$ virus, $81 \%$ for $\mathrm{H} 3 \mathrm{~N} 2$ virus, and $74.1 \%$ for influenza B virus (Table 5). In adults SPR $>70 \%$ and $\mathrm{SCR}<40 \%$ were described for the three vaccine viruses. GMTR $>2.5$ was only found for H1N1 and H3N2 vaccine viruses (Table 5). Adults with pre-immunization $\mathrm{HI}$ antibodies titers $<1: 40$ had significantly higher GMTRs for the three vaccine viruses when compared to those with pre immunization HI antibodies titers $\geq 1: 40$ (H1N1 $p=0.011$; H3N2 $p<0.001$; influenza B $p<0.001$ ) (Table 6).

The SCR for $\mathrm{H} 3 \mathrm{~N} 2$ and influenza $\mathrm{B}$ vaccine viruses were also significantly higher among adults with pre immunization $\mathrm{HI}$ antibodies titers $<1: 40$ when compared 
Table 5 - Pre- and post-vaccination hemagglutination-inhibition antibodies titers, geometric mean titer ratio, seroprotection and seroconversion rates distributed by age group and study year

\begin{tabular}{|c|c|c|c|c|c|c|}
\hline \multirow{3}{*}{ RESULTS } & \multicolumn{2}{|c|}{2013 Study } & \multicolumn{2}{|c|}{2014 Study } & \multicolumn{2}{|c|}{2015 Study } \\
\hline & Adults $(n=42)$ & Elderly $(n=13)$ & Adults $(n=57)$ & Elderly $(n=58)$ & Adults $(n=59)$ & Elderly $(n=56)$ \\
\hline & \multicolumn{2}{|c|}{ (Cl 95\%) } & \multicolumn{2}{|c|}{ (Cl 95\%) } & \multicolumn{2}{|c|}{ (Cl 95\%) } \\
\hline \multicolumn{7}{|c|}{ Pre-vaccination } \\
\hline \multicolumn{7}{|l|}{$\mathrm{HI} \geq 1: 40$} \\
\hline $\mathrm{H} 1 \mathrm{~N} 1$ & $50.0 \%(34.2-65.8)$ & $53.8 \%(25.1-80.8)$ & $84.2 \%(72.1-92.5)$ & $56.9 \%(43.2-69.8)$ & $78.0 \%(65.3-87.7)$ & $39.3 \%(26.5-53.2)$ \\
\hline $\mathrm{H} 3 \mathrm{~N} 2$ & $50.0 \%(34.2-65.8)$ & $30.8 \%(9.1-61.4)$ & $77.2 \%(64.2-87.3)$ & $81.0 \%(68.6-90.1)$ & $57.6 \%(44.1-70.4)$ & $48.2 \%(34.7-62.0)$ \\
\hline B & $50.0 \%(34.2-65.8)$ & $30.8 \%(9.1-61.4)$ & $87.7 \%(76.3-94.9)$ & $74.1 \%(61.0-84.7)$ & $88.1 \%(77.1-95.1)$ & $62.5 \%(48.5-75.1)$ \\
\hline \multicolumn{7}{|l|}{ GMT } \\
\hline $\mathrm{H} 1 \mathrm{~N} 1$ & $31.2(19.3-50.5)$ & $32.3(13.4-77.8)$ & $72.6(54.2-97.2)$ & $31.5(23.3-42.6)$ & $69.5(53.3-90.6)$ & $23.8(17.9-31.5)$ \\
\hline $\mathrm{H} 3 \mathrm{~N} 2$ & $24.0(16.1-35.8)$ & $23.5(10.5-52.5)$ & $74.4(51.4-107.6)$ & $78.1(56.5-108.0)$ & $33.1(23.9-45.9)$ & $29.0(22.1-38.0)$ \\
\hline B & $24.8(17.3-35.5)$ & $18.0(10.8-29.9)$ & $180.7(125.3-260.6)$ & $57.9(44.4-75.7)$ & $81.9(64.8-103.6)$ & $38.5(30.1-49.4)$ \\
\hline \multicolumn{7}{|c|}{ Post-vaccination } \\
\hline \multicolumn{7}{|l|}{$\overline{\text { GMT }}$} \\
\hline $\mathrm{H} 1 \mathrm{~N} 1$ & $167.0(119.0-234.4)$ & $272.7(167.3-444.4)$ & $187.4(145.9-240.8)$ & $123.0(94.0-160.9)$ & $134.1(106.2-169.5)$ & $59.4(45.0-78.5)$ \\
\hline $\mathrm{H} 3 \mathrm{~N} 2$ & $230.0(153.8-344.1)$ & $198.0(99.1-395.7)$ & $209.1(165.3-264.5)$ & $231.7(182.8-293.7)$ & $182.1(140.9-235.3)$ & $178.9(128.6-248.7)$ \\
\hline B & $89.8(67.2-120.0)$ & $80.0(43.2-148.2)$ & $408.1(305.5-545.3)$ & $161.9(125.6-208.8)$ & $143.9(115.0-180.2)$ & $100.0(78.4-127.5)$ \\
\hline \multicolumn{7}{|l|}{ GMTR } \\
\hline $\mathrm{H} 1 \mathrm{~N} 1$ & $5.4(3.52-8.1)$ & $8.4(3.8-19.0)$ & $2.6(2.2-3.1)$ & $3.9(3.1-5.0)$ & $1.9(1.6-2.4)$ & $2.5(2.1-3.0)$ \\
\hline $\mathrm{H} 3 \mathrm{~N} 2$ & $9.6(6.5-14.1)$ & $8.4(3.4-21.0)$ & $2.8(2.1-3.7)$ & $3.0(2.2-3.9)$ & $5.5(4.1-7.3)$ & $6.2(4.7-8.2)$ \\
\hline B & $3.6(2.7-4.8)$ & $4.5(2.4-8.2)$ & $2.3(1.8-2.8)$ & $2.8(2.2-3.5)$ & $1.8(1.5-2.1)$ & $2.6(2.1-3.2)$ \\
\hline \multicolumn{7}{|l|}{ SCR } \\
\hline $\mathrm{H} 1 \mathrm{~N} 1$ & $57.1 \%(41.0-72.3)$ & $76.9 \%(46.2-95.0)$ & $38.6 \%(26.0-52.4)$ & $48.3 \%(35.0-61.8)$ & $15.3 \%(7.2-27.0)$ & $25.0 \%(14.4-38.4)$ \\
\hline $\mathrm{H} 3 \mathrm{~N} 2$ & $78.6 \%(63.2-89.7)$ & $61.5 \%(31.6-86.1)$ & $31.6 \%(19.9-45.2)$ & $37.9 \%(25.5-51.6)$ & $72.9 \%(59.7-83.6)$ & $67.9 \%(54.0-79.7)$ \\
\hline B & $52.4 \%(36.4-68.0)$ & $69.2 \%(38.6-90.9)$ & $17.5 \%(8.7-29.9)$ & $37.9 \%(25.5-51.6)$ & $13.6 \%(6.0-25.0)$ & $39.3 \%(26.5-53.2)$ \\
\hline \multicolumn{7}{|l|}{ SPR } \\
\hline $\mathrm{H} 1 \mathrm{~N} 1$ & $95.2 \%(83.8-99.4)$ & $100 \%(75.3-100)$ & $96.5 \%(87.9-99.6)$ & $93.1 \%(83.3-98.1)$ & $94.9 \%(85.9-98.9)$ & $66.1 \%(52.2-78.2)$ \\
\hline $\mathrm{H} 3 \mathrm{~N} 2$ & $95.2 \%(83.8-99.4)$ & $92.3 \%(64.0-99.8)$ & $98.2 \%(90.6-100)$ & $98.3 \%(90.8-100)$ & $98.3 \%(90.9-100)$ & $87.5 \%(75.9-94.8)$ \\
\hline B & $90.5 \%(77.4-97.3)$ & $92.3 \%(64.0-99.8)$ & $100 \%(93.7-100)$ & $98.3 \%(90.8-100)$ & $96.6 \%(88.3-99.6)$ & $87.5 \%(75.9-94.8)$ \\
\hline
\end{tabular}

Abbreviations: GMT, Geometric Mean Titer; GMTR, Geometric Mean Titer Ratio; SCR, Seroconversion Rate; SPR, Seroprotection Rate.

to those with pre immunization $\mathrm{HI}$ antibodies titers $\geq 1: 40$ (H3N2 $p=0.002$; influenza B $p=0.001$ ). However, there was no significant statistical difference in the SCR for H1N1 vaccine virus $(p=0.075)$ regardless of the pre-immunization $\mathrm{HI}$ antibodies titers (Table 6). In the elderly, SPR $>60 \%$, SCR $>30 \%$ and GMTR $>2.0$ were demonstrated for the three vaccine antigens (Table 5). The elderly with pre-immunization $\mathrm{HI}$ antibodies titers $<1: 40$ had significantly higher GMTRs for H1N1, H3N2 and for influenza $\mathrm{B}$ vaccine viruses when compared to those with pre-immunization $\mathrm{HI}$ antibodies titers $\geq 1: 40$ (H1N1: $p=0.005$; H3N2: $p<0.011 ; \mathrm{B}: p<0.010$ ) (Table 6). The SCR for the three vaccine viruses were also statistically higher among the elderly with pre immunization HI antibodies titers $<1: 40$ when compared to those with pre immunization HI antibodies titers $\geq 1: 40$ (H1N1: $p=0.016$; H3N2: $p=0.001$; B: $p=0.013$ ) (Table 6).

In the 2015 study, 115 (96.6\%) out of 119 participants had pre and post- vaccination blood samples collection, therefore, were included in the immunogenicity analysis: 59 adults and 56 elderly. Before immunization, $78.0 \%$ of the adults had $\mathrm{HI}$ antibodies titers $\geq 1: 40$ for $\mathrm{H} 1 \mathrm{~N} 1,57.6 \%$ for $\mathrm{H} 3 \mathrm{~N} 2$, and $88.1 \%$ for influenza B viruses; among the elderly, $39.3 \%$ had $\mathrm{HI}$ antibodies titers $\geq 1: 40$ for H1N1 virus, $48.2 \%$ for $\mathrm{H} 3 \mathrm{~N} 2$ virus, and $62.5 \%$ for influenza $\mathrm{B}$ virus (Table 5). In adults, SPR $>70 \%$ was achieved for the three vaccine viruses, however, $\mathrm{SCR}>40 \%$ and GMTR $>2.5$ were described only for the H3N2 vaccine virus (Table 5). Adults with pre-immunization $\mathrm{HI}$ antibodies titers $<1: 40$ had significantly higher GMTRs for the three vaccine viruses when compared to those with pre-immunization $\mathrm{HI}$ antibodies titers $\geq 1: 40$ (H1N1: $p=0.002 ; \mathrm{H} 3 \mathrm{~N} 2: p<0.001$; B: $p=0.028$ ) (Table 6).

The SCR for the three vaccine viruses was also significantly higher among adults with pre-immunization $\mathrm{HI}$ antibodies titers $<1: 40$ when compared to those with preimmunization $\mathrm{HI}$ antibodies titers $\geq 1: 40$ (H1N1: $p=0.019$; H3N2: $p=0.001$; B: $p=0.046$ ) (Table 6). In the elderly, SPR $>60 \%$ and GMTR $>2.0$ were demonstrated for the three vaccine antigens, but SCR $>30 \%$ only for the H3N2 and influenza $\mathrm{B}$ viruses (Table 5). The elderly with preimmunization $\mathrm{HI}$ antibodies titers $<1: 40$ had significantly 
Table 6 - Geometric mean titer ratio, seroprotection and seroconversion rates distributed by age group study year and pre-vaccination hemagglutination-inhibition antibodies titers

\begin{tabular}{|c|c|c|c|c|c|c|c|c|c|c|}
\hline \multirow{3}{*}{ RESULTS } & \multicolumn{4}{|c|}{ Adults } & \multirow{3}{*}{$p^{*}$} & \multicolumn{4}{|c|}{ Elderly } & \multirow{3}{*}{$p^{*}$} \\
\hline & \multicolumn{2}{|r|}{$<1: 40$} & \multicolumn{2}{|r|}{$\geq 1: 40$} & & \multicolumn{2}{|r|}{$<1: 40$} & \multicolumn{2}{|r|}{$\geq 1: 40$} & \\
\hline & $\mathrm{n}$ & $(\mathrm{Cl} 95 \%)$ & $\mathrm{n}$ & $(\mathrm{Cl} 95 \%)$ & & $\mathrm{n}$ & $(\mathrm{Cl} 95 \%)$ & $\mathrm{n}$ & $(\mathrm{Cl} 95 \%)$ & \\
\hline \multicolumn{11}{|c|}{2013 Study } \\
\hline \multicolumn{11}{|l|}{ GMTR } \\
\hline $\mathrm{H} 1 \mathrm{~N} 1$ & 21 & $13.6(7.9-23.4)$ & 21 & $2.1(1.6-2.8)$ & $<0.001$ & 6 & $25.4(9.4-68.6)$ & 7 & $3.3(1.6-6.7)$ & 0.009 \\
\hline H3N2 & 21 & $15.0(8.5-26.5)$ & 21 & $6.1(3.8-10.0)$ & 0.023 & 9 & $16.0(5.5-46.4)$ & 4 & $2.0(2.0-2.0)$ & 0.011 \\
\hline B & 21 & $5.9(4.4-8.0)$ & 21 & $2.2(1.5-3.3)$ & $<0.001$ & 9 & $5.4(2.7-11.1)$ & 4 & $2.8(0.4-19.1)$ & 0.337 \\
\hline \multicolumn{11}{|l|}{ SCR } \\
\hline $\mathrm{H} 1 \mathrm{~N} 1$ & 21 & $90.5 \%(69.6-98.8)$ & 21 & $23.8 \%(8.2-47.2)$ & $<0.001$ & 6 & $100 \%(54.1-100)$ & 7 & $57.1 \%(18.4-90.1)$ & 0.192 \\
\hline H3N2 & 21 & $85.7 \%(63.7-97.0)$ & 21 & $71.4 \%(47.8-88.7)$ & 0.454 & 9 & $88.9 \%(51.8-99.7)$ & 4 & $0.0 \%(0.0-60.2)$ & 0.007 \\
\hline B & 21 & $76.2 \%(52.8-91.8)$ & 21 & $28.6 \%(11.3-52.2)$ & 0.005 & 9 & $77.8 \%(40.0-97.2)$ & 4 & $50.0 \%(6.8-93.2)$ & 0.530 \\
\hline \multicolumn{11}{|c|}{2014 Study } \\
\hline \multicolumn{11}{|l|}{ GMTR } \\
\hline $\mathrm{H} 1 \mathrm{~N} 1$ & 9 & $4.3(2.6-7.1)$ & 48 & $2.3(2.0-2.8)$ & 0.011 & 25 & $5.6(3.8-8.2)$ & 33 & $3.0(2.2-4.0)$ & 0.005 \\
\hline H3N2 & 13 & $9.4(4.0-22.1)$ & 44 & $2.0(1.7-2.3)$ & $<0.001$ & 11 & $10.3(3.9-26.9)$ & 47 & $2.2(1.8-2.7)$ & $<0.001$ \\
\hline B & 7 & $8.0(2.5-25.8)$ & 50 & $1.9(1.6-2.2)$ & $<0.001$ & 15 & $4.6(2.7-7.9)$ & 43 & $2.3(1.8-3.0)$ & 0.010 \\
\hline \multicolumn{11}{|l|}{ SCR } \\
\hline $\mathrm{H} 1 \mathrm{~N} 1$ & 9 & $66.7 \%(29.9-92.5)$ & 48 & $33.3 \%(20.4-48.4)$ & 0.075 & 25 & $68.0 \%(46.5-85.1)$ & 33 & $33.3 \%(18.0-51.8)$ & 0.016 \\
\hline H3N2 & 13 & $69.2 \%(38.6-90.9)$ & 44 & $20.5 \%(9.8-35.3)$ & 0.002 & 11 & $81.8 \%(48.2-97.7)$ & 47 & $27.7 \%(15.6-42.6)$ & 0.001 \\
\hline B & 7 & $71.4 \%(29.0-96.3)$ & 50 & $10.0 \%(3.3-21.8)$ & 0.001 & 15 & $66.7 \%(38.4-88.2)$ & 43 & $27.9 \%(15.3-43.7)$ & 0.013 \\
\hline \multicolumn{11}{|c|}{2015 Study } \\
\hline \multicolumn{11}{|l|}{ GMTR } \\
\hline H1N1 & 13 & $3.8(2.0-7.3)$ & 46 & $1.6(1.4-1.9)$ & 0.002 & 34 & $2.9(2.3-3.7)$ & 22 & $2.0(1.6-2.5)$ & 0.044 \\
\hline H3N2 & 25 & $10.6(7.5-14.8)$ & 34 & $3.4(2.4-4.8)$ & $<0.001$ & 29 & $8.0(5.5-11.7)$ & 27 & $4.7(3.1-7.0)$ & 0.053 \\
\hline B & 7 & $3.3(1.4-7.9)$ & 52 & $1.6(1.4-1.9)$ & 0.028 & 21 & $3.7(2.5-5.6)$ & 35 & $2.1(1.6-2.7)$ & 0.014 \\
\hline \multicolumn{11}{|l|}{ SCR } \\
\hline $\mathrm{H} 1 \mathrm{~N} 1$ & 13 & $38.5 \%(13.9-68.4)$ & 46 & $8.7 \%(2.4-20.8)$ & 0.019 & 34 & $29.4 \%(15.1-47.5)$ & 22 & $18.2 \%(5.2-40.3)$ & 0.529 \\
\hline H3N2 & 25 & $96.0 \%(79.6-99.9)$ & 34 & $55.9 \%(37.9-72.8)$ & 0.001 & 29 & $72.4 \%(52.8-87.3)$ & 27 & $63.0 \%(42.4-80.6)$ & 0.570 \\
\hline B & 7 & $42.9 \%(9.9-81.6)$ & 52 & $9.6 \%(3.2-21.0)$ & 0.046 & 21 & $47.6 \%(25.7-70.2)$ & 35 & $34.3 \%(19.1-52.2)$ & 0.401 \\
\hline
\end{tabular}

Abbreviations: GMTR, Geometric Mean Titer Ratio; SCR, Seroconversion Rate. $\left(^{*}\right)$ Mann-Whitney test for GMTR and Fisher's exact test for SCR

higher GMTRs only for the H1N1 and influenza B vaccine viruses when compared to those with pre-immunization $\mathrm{HI}$ antibodies titers $\geq 1: 40$ ( $p=0.044 ; p=0.014$, respectively) (Table 6). However, there was no significant statistical difference in the GMTR for H3N2 vaccine virus ( $p=0.053$ ) regardless of the pre-immunization $\mathrm{HI}$ antibodies titers (Table 6). There was no statistically significant difference in the SCR, for the three viruses, when one elderly with pre-immunization $\mathrm{HI}$ antibodies titers $<1$ : 40 were compared to those with pre-immunization $\mathrm{HI}$ antibodies titers $\geq 1: 40$ (H1N1: $p=0.529 ; \mathrm{H} 3 \mathrm{~N} 2: p=0.570$; influenza B: $p=0.401$ ) (Table 6).

\section{DISCUSSION}

Annual vaccination is recommended by WHO as the most effective way of preventing seasonal influenza. In Brazil, the National Immunization Program of the Ministry of Health has carried out annual national influenza vaccine campaigns since 1999. Currently, IB is one of the main public producers of seasonal trivalent influenza vaccine (inactivated split-virion) in the world and has delivered it to the annual influenza vaccination campaign of the National Immunization Program.

From 2013 to 2015, the Brazilian Regulatory Health Authority (Agência Nacional de Vigilância Sanitária - ANVISA) requested IB to perform post-licensure prospective cohort studies to evaluate the safety and immunogenicity of the 2013, 2014, and 2015 seasonal influenza vaccines in health adults and people over 60 years of age. The sample size for each annual study was established in accordance with ANVISA and followed the EMA's recommendations for clinical evaluation of trivalent seasonal influenza vaccine. The number of participants in the 2013 study was lower compared to the number of participants in the 2014 and 2015 studies. However, this did not affect the results because the safety and immunogenicity data described for the three years were similar. This confirms that post-licensure surveillance (pharmacovigilance activities) is more appropriate for the detection of rare or unexpected safety signals and effectiveness data of the seasonal influenza vaccines and 
they should be obtained through classic efficacy trials and not be based only on immunogenicity data.

Among the strategies of the Division of Clinical Trials and Pharmacovigilance of IB for conducting clinical studies with immunobiological products produced by the IB is the establishment of partnerships with national institutions linked to the Unified Health System (SUS), such as Brazilian universities and the Adolfo Lutz Institute. These partnerships have made it possible to integrate basic immunobiological research, vaccine development and production, and clinical studies, thus completing the innovation process characterized by the availability of vaccines produced by Brazilian public laboratories for SUS.

The 2013, 2014 and 2015 influenza vaccine studies included the participation of the Adolfo Lutz Institute, the CRIE-HCFMUSP and ICR-HCFMUSP. The total number of participants in the three studies was 299: 60 in 2013; 120 in 2014; and 119 in 2015. The 2013 study was the one with the lowest number of participants (47 adults and 13 elderly) probably due to the late start of the study in the clinical site when the influenza annual immunization campaign was already close to the end.

Overall, the vaccines were well-tolerated with no unexpected events or new safety signals. Only in the 2014 and 2015 studies, the incidence of adverse reactions was statistically higher in adults when compared to the elderly. The adverse reactions observed in adults and elderly, in the three studies, were classified as mild or moderate, and no severe adverse reaction was reported. Besides, they were predominantly observed within $24 \mathrm{~h}$ after vaccination and disappeared up to seven days. These findings have also been demonstrated for other trivalent seasonal influenza vaccines (split-virion, inactivated) $^{12,13}$.

The most frequent adverse reactions, in the three studies, were local pain at the injection site and headache, both in adults and in the elderly. These adverse reactions have also been described in the literature for other trivalent seasonal influenza vaccines (split-virion, inactivated) $)^{14-17}$. Fever had a low incidence in the three studies; it is known to be associated with trivalent inactivated influenza vaccines but is not considered a serious event nor is associated with complications $^{18}$.

According to EMA's recommendations ${ }^{7,8}$, trivalent seasonal influenza vaccine (split-virion inactivated) is considered immunogenic when one of the following parameters is demonstrated: a) in adults: SCR $>40 \%$ and/or SPR $>70 \%$, and/or HI antibody GMTR $>2.5$; b) in the elderly: SCR $>30 \%$ and/or SPR $>60 \%$ and/or $\mathrm{HI}$ antibody GMTR $>2.0$.

In 2013, the vaccine immunogenicity in adults was demonstrated for the three vaccine viruses by SPR $>70 \%$,
SCR $>40 \%$ and GMTR $>2.5$; in 2014, by SPR $>70 \%$; and in 2015 by SPR $>70 \%$. For the elderly, in 2013 and 2014 the vaccine immunogenicity was demonstrated for the three vaccine by $\mathrm{SPR}>60 \%$, SCR $>30 \%$ and GMTR $>2.0$; and in 2015 by SPR $>60 \%$ and GMTR $>2.0$.

Surprisingly, adequate seroconversion frequency values were not observed for the three vaccine viruses among adults in the 2014 study and specifically for the H1N1 and influenza B viruses in the 2015 study. However, when one analyses the frequency of seroconversion in the 2014 study among adults, significantly higher values of this frequency were observed for $\mathrm{H} 3 \mathrm{~N} 2$ and influenza B vaccine viruses among participants who had pre-immunization $\mathrm{HI}$ antibodies titers $<1: 40$ compared to those with pre-immunization HI antibodies titers $\geq 1: 40$. Furthermore, the frequency of seroconversion ended up being greater than $40 \%$ among those with pre-immunization HI antibodies titers <1:40. In the 2015 study, significantly higher seroconversion rates were also observed for H1N1 and influenza B vaccine viruses in adults with pre-immunization $\mathrm{HI}$ antibodies titers $<1: 40$ compared to those with pre-immunization HI antibodies titers $=1: 40$. However, a frequency of seroconversion $>40 \%$ for the H1N1 vaccine virus among adults with pre-immunization $\mathrm{HI}$ antibodies titers $<1: 40$ antibody was not observed. These findings suggest that, in adults, the level of pre-immunization HI antibodies may impact on the frequency of seroconversion to influenza vaccination and that this impact is strain-specific.

\section{CONCLUSION}

The results of this study demonstrated that the 2013, 2014 and 2015 seasonal influenza vaccines (inactivated split-virion) produced integrally by the IB were overall welltolerated and safe, since no unexpected events or new safety signs were observed. In addition, these vaccines have been shown to be immunogenic based on the immunogenicity criteria defined by the EMA. The satisfactory safety and immunogenicity profiles demonstrated over the three study years confirmed the production consistency of the seasonal influenza vaccine (inactivated split-virion) by the IB.

\section{ACKNOWLEDGMENTS}

Our acknowledgments to all the study participants, the researchers from the clinics, from the laboratory that performed the assays and the colleagues from the Division of Clinical Trials and Pharmacovigilance from Instituto Butantan. We thank all the institutions involved: Instituto Butantan, Fundação Butantan, Instituto Adolfo Lutz, CRIE-HCFMUSP, and ICR-HCFMUSP. 


\section{CONFLICT OF INTERESTS}

The authors state that there is no conflict of interests.

\section{REFERENCES}

1. World Health Organization. Influenza (Seasonal). Geneva: WHO; 2018. [cited 2018 Jul 2]. Available from: http://www.who.int/ news-room/fact-sheets/detail/influenza-(seasonal)

2. Constantino C, Vitale F. Influenza Vaccination in high-risk groups: a revision of existing guidelines and rationale for an evidencebased preventive strategy. J Prev Med Hyg. 2016;57:E13-8.

3. Centers for Disease Control and Prevention. Prevention and control of seasonal influenza with vaccines: recommendations of the Advisory Committee on Immunization Practices - United States, 2013-2014. Atlanta: CDC; 2013. [cited 2018 July 2]. Available from: https://www.cdc.gov/mmwr/pdf/rr/rr6207.pdf

4. Brasil. Ministério da Saúde. Secretaria de Vigilância da Saúde. Informe técnico: Campanha Nacional de Vacinação Contra a Influenza. Brasília: Ministério da Saúde; 2016. [cited 2018 Jul 2]. Available from: http://portalarquivos2.saude.gov.br/images/ pdf/2016/marco/11/informe-tecnico-campanha-vacinacaoinfluenza-2016.pdf

5. Brasil. Ministério da Saúde. Secretaria de Vigilância da Saúde. Informe técnico: Campanha Nacional de Vacinação Contra a Influenza. Brasília: Ministério da Saúde; 2014. [cited 2018 Jul 2]. Available from: http://portalarquivos2.saude.gov.br/images/ pdf/2015/junho/26/Informe-Campanha-Influenza---Atualiza---o-25-03-2014-final.pdf

6. European Medicines Agency. Integrated addendum to ICH E6Rr1: guideline for good clinical practice E6(R2). London: EMA; 2016. [cited 2018 Jul 2]. Available from: https://www.ich. org/fileadmin/Public_Web_Site/ICH_Products/Guidelines/ Efficacy/E6/E6_R2_Step_4_2016_1109.pdf

7. European Medicines Agency. Note for guidance on harmonization of requirements for influenza vaccines. London: EMA; 1997. [cited 2018 Jul 2]. Available from: http://academy.gmpcompliance.org/guidemgr/files/021496EN.PDF

8. European Medicines Agency. Guideline on influenza vaccines: non-clinical and clinical module. London: EMA; 2016. [cited 2018 Apr 6]. Available from: http://www.ema.europa.eu/ docs/en_GB/document_library/Scientific_guideline/2016/07/ WC500211324.pdf

9. World Health Organization. Uppsala Monitoring Centre. The use of the WHO-UMC system for standardised case causality assessment. Geneva: WHO; 2014. [cited 2018 Jul 2]. Available from: https://who-umc.org/media/164200/who-umc-causalityassessment_new-logo.pdf

10. United States of America. Department of Health and Human Services. Food and Drug Administration. Center for Biologics Evaluation and Research. Guidance for industry: toxicity grading scale for healthy adult and adolescent volunteers enrolled in preventive vaccine clinical trials. Rockville: DHHS; 2017. [cited 2018 Jul 2]. Available from: https://www.fda.gov/ downloads/BiologicsBloodVaccines/ucm091977

11. World Health Organization. Global epidemiological surveillance standards for influenza. Geneva: WHO; 2014. [cited 2018 Jul 2]. Available from: http://www.who.int/influenza/resources/ documents/WHO_Epidemiological_Influenza_Surveillance_ Standards_2014.pdf

12. Anh DD, Thiem VD, Anh NT, Huong VM, Nga NT, Thang TC, et al. Randomized safety and immunogenicity trial of a seasonal trivalent inactivated split virion influenza vaccine (IVACFLU-S) in healthy young vietnamese adults. Vaccine. 2016;34:5457-62.

13. Haugh M, Gresset-Bourgeois V, Macabeo B, Woods A, Samson SI. A trivalent, inactivated influenza vaccine (Vaxigrip ${ }^{\circledR}$ ): summary of almost 50 years of experience and more than 1.8 billion doses distributed in over 120 countries. Expert Rev Vaccines. 2017;16:545-64.

14. Latreille-Barbier M, Rouzier R, Astruc B, Lavis N, Donazzolo Y. Immunogenicity and safety of the Southern Hemisphere 2015 formulation of Vaxigrip®. Hum Vaccin Immunother. 2017;13:2674-7.

15. Jackson LA, Gaglani MJ, Keyserling HL, Balser J, Bouveret $\mathrm{N}$, Fries L, et al. Safety, efficacy, and immunogenicity of an inactivated influenza vaccine in healthy adults: a randomized, placebo-controlled trial over two influenza seasons. BMC Infect Dis. 2010;10:71.

16. Mo Z, Nong Y, Liu S, Shao M, Liao X, Go K, et al. Immunogenicity and safety of a trivalent inactivated influenza vaccine produced in Shenzhen, China. Hum Vaccin Immunother. 2017;13:1272-8.

17. Kang K, Han S, Hong T, Jeon S, Paek J, Kang JH, et al. Immunogenicity and safety of trivalent split influenza vaccine in healthy Korean adults with low pre-existing antibody levels: an open phase I trial. Yonsei Med J. 2016;57:1354-60.

18. Glanz JM, Newcomer SR, Hambidge SJ, Daley MF, Narwaney KJ, $\mathrm{Xu} \mathrm{S}$, et al. Safety of trivalente inactivated influenza vaccine in children aged 24 to 59 months in the vaccine safety datalink. Arch Pediatr Adolesc Med. 2011;165:749-55. 